\title{
INFLUÊNCIA DA CONCENTRAÇÃO DE HIDRÓXIDO DE SÓDIO NA SÍNTESE DE GEOPOLÍMERO USANDO A ESCÓRIA COMO PRECURSOR
}

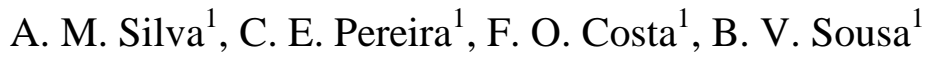 \\ ${ }^{1}$ Universidade Federal de Campina Grande, Departamento de Engenharia Química. \\ andre.equfcg@gmail.com
}

\begin{abstract}
RESUMO - A busca por materiais cimentícios alternativos vem crescendo atualmente visando uma redução do consumo de cimento Portland, devido ao impacto ambiental. Com base nesse argumento, essa pesquisa avaliou a escória para a síntese de geopolímeros. A obtenção do material geopolimérico é realizada através de reações que envolvam materiais nos quais em suas composições apresentam alumina-silicato que serão ativados por soluções alcalinas. O objetivo é a comparação dos materiais geopoliméricos, utilizando diferentes concentrações da solução ativadora. Para verificar o seu efeito foi necessária a caracterização do resíduo através da espectroscopia de raios $\mathrm{X}$ por energia dispersiva e difratometria de raios $\mathrm{x}$, e a caracterização do cimento geopolimérico obtido foi através da difratometria de raios $X$, microscopia eletrônica de varredura e ensaios de resistência à flexão. Os resultados mostram um efeito significativo da concentração do ativador alcalino.
\end{abstract}

Palavras-chave: geopolímero, escória, ativador alcalino.

\section{INTRODUÇÃO}

Geopolímeros são geralmente preparados por mistura de aluminosilicato com uma solução alcalina de silicato seguido de cura a temperatura ambiente (Romagmoli et al, 2012). Os materiais residuais como cinzas volantes, escória de forno e resíduos de minerais contêm quantidades suficientes de alumina e sílica reativas que podem ser usados como materiais de partida para reações de geopolimerização (Ribeiro, 2012).

A escolha do tipo de álcali a ser utilizado durante a síntese dependerá de muitos fatores, sendo o fator mais importante o tipo de material de partida a ser utilizado, bem como o objetivo final em termos de aplicação (Marinho, 2004). Van Jaarsveld (2000) afirma que cátions de metais alcalinos controlam e afetam quase todas as fases da geopolimerização e em particular durante a fase gel, endurecimento e formação de cristais.

Os ativadores a base de silicato promovem uma aceleração na reação geopolimérica, pelo fato da sílica presente iniciar a reação com a alumina livre na solução. O silicato favorece o processo de polimerização, levando a um produto de reação com mais Si e maior resistência mecânica (Criado, 2005). 
Os aluminossilicatos, sob condições alcalina, são transformados em materiais extremamente reativos devido ao processo de dissolução de diferentes espécies de silicatos e aluminatos. A polimerização das espécies é favorecida pela elevada concentração de hidroxila, pois estas facilitam a dissociação das espécies (Phair et al., 2000).

Duxson et al (2005), mostrou que o sódio presente na solução alcalina, quando incorporado na matriz geopolimérica tem função de proporcionar o balanceamento de carga da rede formada pelos tetraedros de silício e alumínio. Como o alumínio apresenta valência $\left(3^{+}\right)$menor do que a do silício $\left(4^{+}\right)$, a estrutura do aluminossilicato apresenta uma carga negativa para cada átomo de alumínio. Esta carga é balanceada por cátions alcalinos ou alcalino-terrosos, chamados de cátions de compensação, intersticiais ou trocáveis, normalmente o $\mathrm{Na}^{+}, \mathrm{K}^{+}$ou $\mathrm{Ca}^{2+}$, que são livres para se moverem nos canais ou cavidades da rede e podem ser trocados por outros cátions em solução (Izumi et al, 1992).

Durante a síntese, os cátions de metais alcalinos desempenham um papel muito importante na ordenação das moléculas de água e, depois, na solubilização das espécies para começar o processo de nucleação que conduzirá à formação da estrutura. $\mathrm{O}$ tamanho do cátion, também afeta a morfologia do eventual cristal, sendo o potássio responsável por um maior grau de condensação, quando comparado ao sódio, sob as mesmas condições (Marinho, 2004). $\mathrm{O} \mathrm{Na}^{+}$tendo um tamanho menor que o que $\mathrm{K}^{+}$ exibe formação de pares com menores oligômeros de silicato (tais como monômeros). Observa-se que quanto maior o tamanho do cátion, por exemplo, $\mathrm{K}^{+}$, mais favorecida é a formação de maiores oligômeros de silicato na qual o $\mathrm{Al}(\mathrm{OH})^{-4}$ prefere se ligar. Por conseguinte, precursores ativados com $\mathrm{KOH}$ apresentam maior resistência à compressão em comparação com geopolímeros sintetizados a partir de soluções de $\mathrm{NaOH}$ (Phair, 2002).

Baseado nesse contexto, este trabalho teve como objetivo avaliar a influência da concentração do ativador $(\mathrm{NaOH})$ nas propriedades mecânicas do geopolímero.

\section{MATERIAIS E MÉTODOS}

\subsection{Materiais}

Os materiais utilizados para a preparação do geopolímero foram escória, metasilicato de sódio, solução de hidróxido de sódio e água destilada. A escória foi utilizada como precursor; o metasilicato de sódio foi usado como fonte alternativa de silício e soluções de hidróxido de sódio para garantir o pH alcalino desejado.

\subsection{Métodos}

Preparação do material geopolimérico: Para a obtenção do material geopolimérico foi realizada as seguintes etapas: a escória, a solução de metassilicato de sódio e a solução de hidróxido de sódio foram misturadas manualmente com água destilada e em seguida manteve-se sob agitação mecânica até obter uma mistura homogênea. $O$ material obtido foi transferido para o molde e submetido a um tratamento térmico em estufa por $24 \mathrm{~h}$ a $60{ }^{\circ} \mathrm{C}$, após esse período o material permaneceu curando em 
temperatura ambiente durante 7 dias. As superfícies dos moldes foram cobertas com filme de polietileno. Para evitar a evaporação excessiva da água na ativação alcalina na amostra durante a cura térmica (BARBOSA, 1999). Foram utilizadas três concentrações de hidróxido de sódio: $6 \mathrm{~mol} / \mathrm{L}, 8 \mathrm{~mol} / \mathrm{L}$ e 10mol/L, as quais foram obtidos o Geo 6 , o Geo 8 e o Geo 10 respectivamente.

\subsection{Caracterização}

Espectroscopia de raios $X$ por energia (EDX): A análise química foi realizada através do espectrômetro de raios X por energia dispersiva - EDX- 700 da marca Shimadzu. Esse ensaio consiste em determinar a composição química do material em termos qualitativo e semiquantitativo. Antes da análise a amostra foi desaglomerada em almofariz e passada em peneira ABNT n 200 (aberturas 0,074 mm). O resultado da análise química foi expresso em óxidos.

Difratometria de raios-X (DRX): O aparelho utilizado foi XRD 6000 da marca Shimadzu, com radiação $\mathrm{K}$ do cobre, tensão de $40 \mathrm{KV}$, corrente de $30 \mathrm{~mA}$, tamanho do passo de 0,020 e tempo por passo de 1,000s. A amostra foi varrida na faixa de $2 \theta$ de 4 a $45^{\circ}$. Os valores de espaçamentos interplanares $\mathrm{d}_{(\mathrm{hkl})}$ podem ser obtidos usando a Lei de Bragg, Equação 1:

$$
\text { n. } \lambda=2 \cdot \mathrm{d}_{(\mathrm{hKl})} \operatorname{sen} \theta
$$

Em que:

Comprimento de onda $(\lambda)=1,5418 \AA$;

$\mathrm{d}_{(\mathrm{hkl})}$ : distância entre o índice de planos (hkl);

hkl: índice de Miller;

Microscopia eletrônica de varredura (MEV): As analises foram realizadas no aparelho da Shimadzu SSX-55. Para a obtenção das micrografias, os corpos de provas foram cortados em formas quadráticas na superfície do material.

Resistência à flexão: Os ensaios de resistência mecânica foram realizados em um equipamento de ensaios universais da Shimadzu, as amostras foram feitas de forma cilíndricas com dimensões de $50 \mathrm{~mm}$ de altura e $20 \mathrm{~mm}$ de diâmetro.

\section{RESULTADOS E DISCUSSÃO}

\subsection{Composição química do metasilicato}

A Tabela 1 apresenta a composição química do metasilicato de sódio puro $\left(\mathrm{Na}_{2} \mathrm{SiO}_{3} \mathrm{XH}_{2} \mathrm{O}\right)$. 
Tabela 1 - Composição química do metasilicato.

\begin{tabular}{c|c}
\hline Componentes & Concentração \%-massa \\
\hline $\mathrm{Na}_{2} \mathrm{O}$ & $20-30$ \\
$\mathrm{SiO}_{2}$ & $20-30$ \\
$\mathrm{H}_{2} \mathrm{O}$ & $20-60$ \\
\hline
\end{tabular}

A partir dos dados da Tabela 1 observou-se que o metasilicato apresentou uma fonte suplementar de silício $\left(\mathrm{SiO}_{2}\right)$ entre 20 e $30 \%$.

\subsection{Caracterização da Escória}

Espectroscopia de raios X por energia (EDX): A Tabela 2 apresenta a composição química, na forma de óxidos, das amostras do resíduo de escória, para ser aplicado na obtenção do material geopolimérico.

Tabela 2 - Composição química da amostra de resíduo da escória.

\begin{tabular}{c|c}
\hline Componentes & Concentração \%-massa \\
\hline $\mathrm{CaO}$ & 39,87 \\
$\mathrm{Fe}_{2} \mathrm{O}_{3}$ & 27,65 \\
$\mathrm{SiO}_{2}$ & 11,02 \\
$\mathrm{MgO}$ & 8,23 \\
$\mathrm{Al}_{2} \mathrm{O}_{3}$ & 4,62 \\
$\mathrm{P}_{2} \mathrm{O}_{5}$ & 1,66 \\
$\mathrm{TiO}_{2}$ & 0,48 \\
$\mathrm{SO}_{3}$ & 0,39 \\
Outros & 0,65 \\
\hline
\end{tabular}

A partir dos dados da Tabela 2 observou-se que a escória apresentou óxidos de cálcio, ferro, silício, magnésio e alumínio. A escória é o precursor geopolimérico, ou seja, o fornecedor de aluminosilicatos $\left(\mathrm{Al}_{2} \mathrm{O}_{3}, \mathrm{SiO}_{2}\right)$ necessários para a reação de geopolimerização, constatou-se que a escória empregada possui, em média 15,44\% destes dois óxidos. Através dessa caracterização é possível saber a composição química da escória e assim calcular a formulação do material geopolimérico.

Difratometria de raios-X (DRX): $O$ resultado de difratometria de raios $\mathrm{X}$ do material é apresentado na Figura 1. 


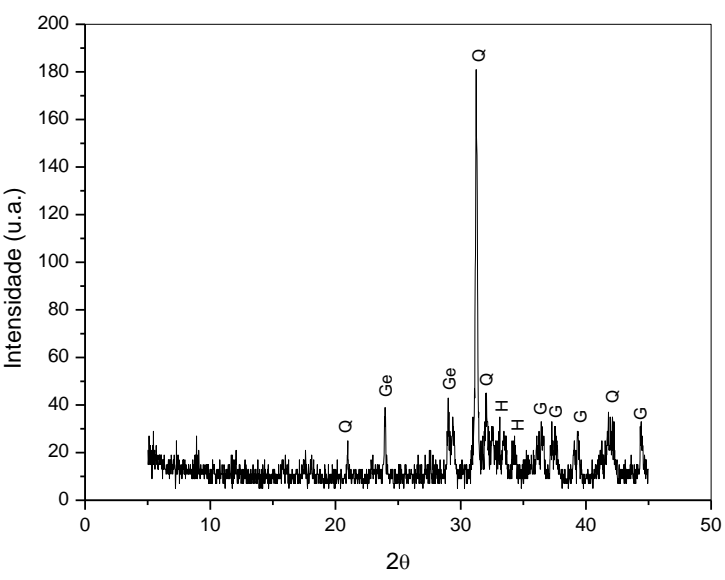

Figura 2 - Difratograma do resíduo de escória.

Legenda: $\mathrm{Ge}=$ gehlenita, $\mathrm{H}=$ hematita, $\mathrm{G}=$ gibbsita e $\mathrm{Q}=$ quartzo.

Analisando o difratograma é possível observar picos a (4,23, 2,85, 2,78, 2,16 e $2,03 \AA$ ) que são característicos da presença de sílica $\left[\mathrm{SiO}_{2}\right]$ na forma de quartzo. Nos picos $\left(3,71\right.$, e 3,07 $\AA$ ), foi caracterizado a presença da gehlenita $\left[\mathrm{Ca}_{2} \mathrm{Al}_{2} \mathrm{SiO}_{2}\right]$.

Os picos apresentados no resíduo (2,70 e 2,67 ̊̊) são característicos da hematita $\left[\mathrm{Fe}_{2} \mathrm{O}_{3}\right]$. Os picos $\left(2,41,2,29\right.$ e 2,03 $\AA$ ) caracteriza a presença de gibbsita $\left[\mathrm{Al}(\mathrm{OH})_{3}\right]$.

\subsection{Caracterização do Material Geopolimérico}

Difratometria de Raios-X (DRX): O resultado de difratometria de raios $\mathrm{X}$ dos materiais geopoliméricos é apresentado na Figura 2.

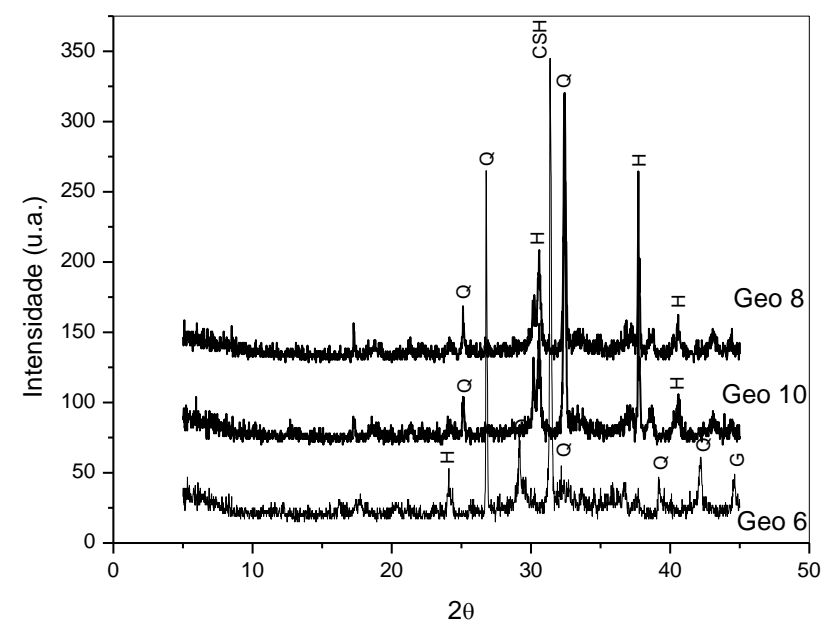

Figura 2 - Difratogramas dos materiais geopoliméricos Geo 6, Geo 8 e Geo 10. Legenda: $\mathrm{H}=$ hematita, $\mathrm{G}$ = gibbsita, $\mathrm{CSH}=$ silicato de cálcio hidratado, $\mathrm{Q}=$ quartzo. 
Através do difratograma do Geo 6 é possível observar pico a $(3,70$ A $)$ característico da hematita $\left[\mathrm{Fe}_{2} \mathrm{O}_{3}\right]$. A presença de sílica $\left[\mathrm{SiO}_{2}\right]$ foi caracterizada nos picos $(3,33,2,85,2,30$ e $2,14 \AA)$ na forma de quartzo. E, no pico $(2,02 \AA)$ foi caracterizado a presença de gibbsita $\left[\mathrm{Al}(\mathrm{OH})_{3}\right]$. O pico apresentado no material Geo 6 $(3,07 \AA)$ evidencia que o cálcio reagiu com a $\mathrm{SiO}_{2}$ na presença da solução alcalina $(\mathrm{NaOH})$ formando o silicato de cálcio hidratado $(\mathrm{C}-\mathrm{S}-\mathrm{H})$ que caracteriza a formação do geopolímero (LECOMTE et al, 2006).

Analisando os difratogramas do Geo 8 e Geo 10 é possível observar picos a (3,54 e 2,76 ̊̊) que são característicos da presença de sílica na forma de quartzo. Nos picos $(2,92,2,38$ e $2,22 \AA)$ foi caracterizado a presença de hematita $\left[\mathrm{Fe}_{2} \mathrm{O}_{3}\right]$.

Microscopia Eletrônica de Varredura (MEV): A Figura 3 mostra as micrografias com ampliação de 500x do geopolímero sintetizado.

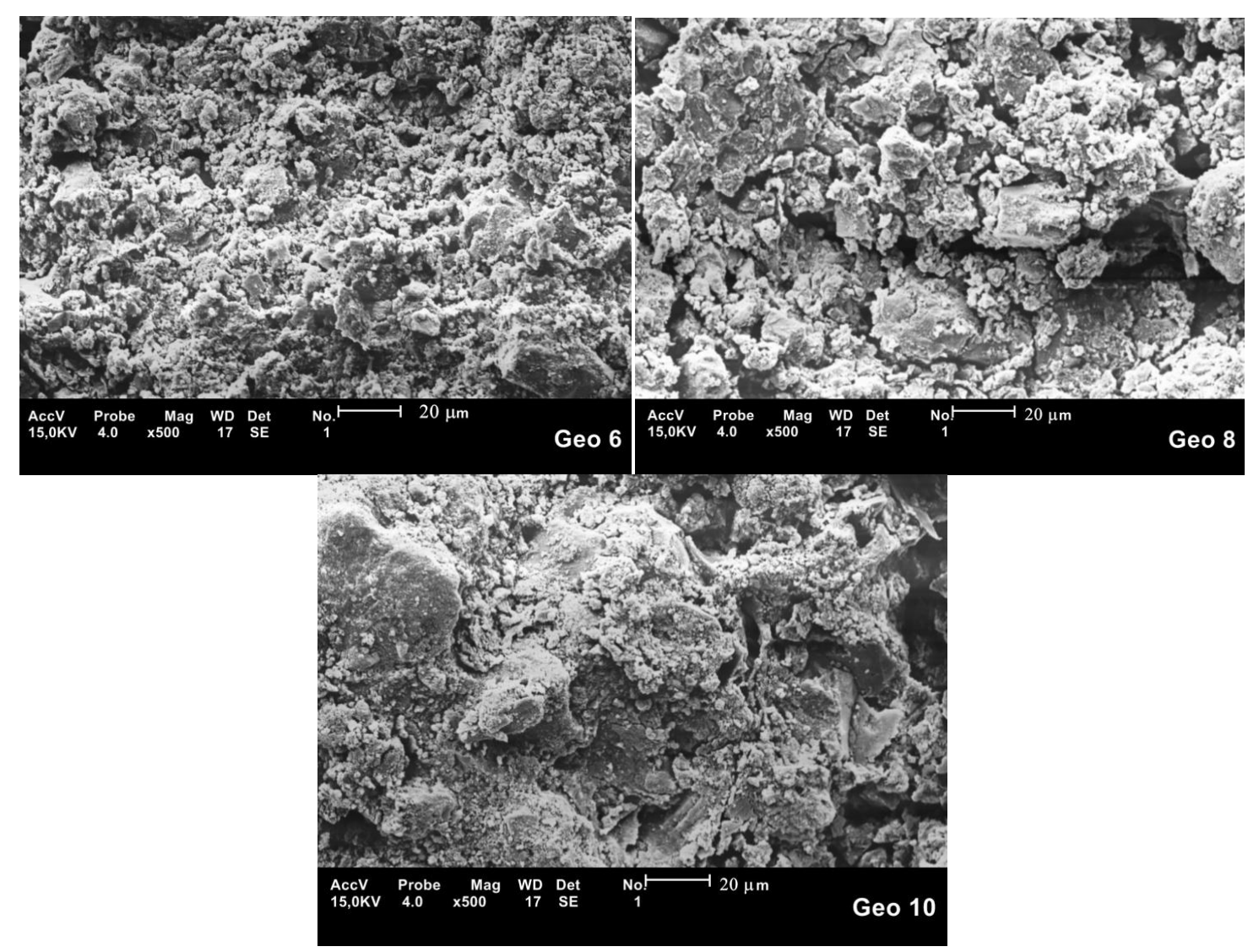

Figura 3 - Micrografias dos materiais geopoliméricos Geo 6, Geo 8 e Geo 10.

Observa-se na micrografia Geo 6 uma estrutura mais compactada, o que explica o fato desta amostra apresentar uma maior resistência mecânica. Nas micrografias Geo 8 e Geo 10 observa-se uma quantidade maior de espaços vazios entre os agregados de partículas com morfologia indefinida. Estas superfícies com espaços vazios podem está interferindo na resistência mecânica, pois favorece a ruptura do material com mais facilidade. Portanto, o fator influenciado pela concentração do ativador alcalino irá afetar significativamente as propriedades mecânicas do material geopolimérico. 
Resistência à flexão: A Figura 4 apresenta a resistência mecânica à flexão dos materiais geopoliméricos, com os ativadores alcalinos $6 \mathrm{~mol} / \mathrm{L}, 8 \mathrm{~mol} / \mathrm{L}$ e $12 \mathrm{~mol} / \mathrm{L} \mathrm{e}$ tempo de cura com 7 dias.

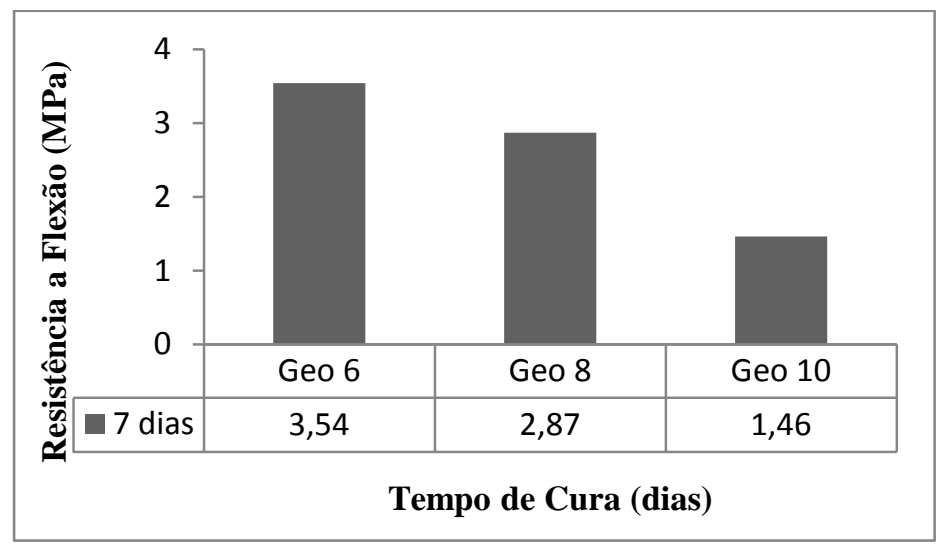

Figura 4 - Resistência à flexão dos materiais geopoliméricos sintetizados, com tempo de cura de 7 dias.

A partir dos resultados observados na Figura 4, verificou-se que o maior valor de resistência a flexão do material geopolimérico no período de 7 dias de cura foi de 3,54 MPa para o Geo 6, cuja concentração do ativador alcalino foi de $6 \mathrm{~mol} / \mathrm{L}$. Para os outros materiais geopoliméricos (Geo 8 e Geo 10), cujas concentrações são 8 mol/L e $10 \mathrm{~mol} / \mathrm{L}$ respectivamente, observou-se que com o mesmo tempo de cura houve uma diminuição do valor da resistência.

Portanto foi investigada a resistência de materiais geopoliméricos de escória álcali ativadas com hidróxido de sódio e silicato de sódio, onde foi verificado que para cura a temperatura ambiente, ambos são necessários para a obtenção de uma elevada resistência. A concentração da solução de $\mathrm{NaOH}$ influencia diretamente na velocidade de ganho de resistência, uma vez que afeta a taxa e a quantidade de dissolução da escória. Comprovou-se que das concentrações de $\mathrm{NaOH}$ analisadas a melhor resistência à flexão foi para o material geopolimérico, cuja concentração de ativador foi de 6 $\mathrm{mol} / \mathrm{L}$.

\section{CONCLUSÃO}

Através do EDX observou a composição química do precursor, evidenciando a presença de grupos silicatos e aluminatos, componentes essenciais para a síntese de material geopolimérico, além de evidenciar que o componente em maior quantidade no precursor foi o $\mathrm{CaO}$, sendo esse componente importante pois o principal produto da reação de geopolimerização é o CSH (silicato de cálcio hidratado). Na caracterização do material geopolimérico pode-se confirmar no difratograma a presença do silicato de cálcio que corresponde à formação do geopolímero. Na micrografia foi possível identificar que a morfologia do material é um indicativo de que a concentração do ativador alcalino influência nas propriedades mecânicas do material. E o teste de 
resistência comprovou que o melhor comportamento de rompimento do geopolímero foi de 3,54 MPa para 7 dias empregando a concentração de ativador alcalino de $6 \mathrm{~mol} / \mathrm{L}$.

\section{AGRADECIMENTOS}

Os autores deste trabalho agradecem ao CAPES/DEQ/UAEQ/UAEM/UFCG.

\section{REFERÊNCIAS}

BARBOSA, V. F. F. Síntese e caracterização de Polissialatos. 1999, 150p. Tese (Doutorado em Engenharia de Materiais) - Instituto Militar de Engenharia, IME/RJ, Rio de Janeiro.

CRIADO, M.; PALOMO, A.; FERNÁNDEZ-JIMÉNEZ, A. Alkali activation of fly ashes. Part I: Effect of curing conditions on the carbonation of the reaction products. $J$. of Cem. and Com. Comp., v. 84, p.2048 - 2054, 2005.

DUXSON, P.; LUKEY G.; SEPAROVICc F.; VAN DEVENTER J., Effect of alkali cations on aluminum incorporation in geopolymeric gels. Ind. Eng. Chem. Res., v. 44, p. $832,2005$.

IZUMI, Y.; URABE, K.; ONAKA, M., Zeolite, Clay, and Heteropoly Acid in Organic Reactions, 1992. 166 S., geb. 128.00 DM. - ISBN 3-527-29011-7, VCH: New York.

LECOMTE, I.; HENRISTC.; LIÉGEOIS, M.; MASARI, F.; RULMONT, A.; CLOOTS, R., (Micro)-structural comparison between geopolymers, alkali-activated slag cement and Portland cement. J. of the Euro. Cer. Soc., v. 26, p. 3789-3797, 2006.

MARINHO, E.P. Desenvolvimento de pastas geopoliméricas para cimentação de poços de petróleo. 2004, Tese (Doutorado em Centro de Ciências Exatas e da Terra) Universidade Federal do Rio Grande do Norte, UFRN/RN, Natal.

PHAIR, J. W.; VAN DEVENTER, J. S. J.; SMITH, J. D., Mechanism of polysialation in the incorporation of zirconia into fly ash-based geopolymers. Ind. Eng. Chem. Res., v. 39, p.2925-2934, 2000.

PHAIR, J. W.; VAN DEVENTER, J. S. J., Characterisation of fly-ash-based geopolymeric binders activated with sodium aluminate. Ind. Eng. Chem. Res., v. 41, p. $4242-4251,2002$.

ROMAGNOLI, M.; LEONELLI, C.; KAMSE E.; GUALTIERI M. L., Rheology of Geopolymer by DOE approach. Cons. and Buil. Mat. v. 36 p 251-258, 2012.

RIBEIRO, D. B., Influência da adição de cálcio nas propriedades de pastas geopoliméricas destinadas a cimentação de poços de petróleo. 2012, 69p. Dissertação (Mestrado em Ciência e Engenharia de Materiais) - Universidade Federal do Rio Grande do Norte, UFRN/RN, Natal.

VAN JAARSVELD, J. G. S.; LUKEY, G. C.; VAN DEVENTER, J. S. J., The stabilization of mine tailings by reactive geopolymerisation. AusIMM., v. 5, p. 363$371,2000$. 